\title{
Prevalence of psoriatic arthritis and costs generated by treatment of psoriatic arthritis patients in the public health system - the case of Poland
}

\section{Filip Raciborski ${ }^{1}$, Andrzej Śliwczyński², Anna Kłak ${ }^{1}$, Brygida Kwiatkowska³ ${ }^{3}$ Melania Brzozowska², Małgorzata Tłustochowicz ${ }^{4}$}

${ }^{1}$ Department of Gerontology and Public Health, National Institute of Geriatrics, Rheumatology and Rehabilitation, Warsaw, Poland ${ }^{2}$ Department of Medical Standards, Procedures and Quality, Health Sciences Faculty, Medical University of Lodz, Poland Departament of Analyses and Strategy, Central Office of National Health Fund, Lodz, Poland

${ }^{3}$ Clinic of Early Arthritis, National Institute of Geriatrics, Rheumatology and Rehabilitation, Warsaw, Poland

${ }^{4}$ Department of Internal Medicine and Rheumatology, Military Institute of Medicine Warsaw, Poland

\begin{abstract}
Objective: The objective of the study was to analyse the prevalence of psoriatic arthritis (PSA) in Poland and to assess the costs generated by treatment of PSA patients in the system of public healthcare.

Material and methods: The analysis was based on the database of the public payer, the National Health Fund (NFZ). PsA was defined by the diagnostic ICD-10 codes M07 (Enteropathic arthropathies) and L40.5 (Psoriatic arthropathies). The estimate of the costs was based on the reports submitted to the NFZ by health service providers. The prevalence rates were calculated using the NFZ data and the population estimates from the Central Statistical Office of Poland (GUS).

Results: In 2015, the prevalence of PSA (ICD-10: L40.5 and M07) in Poland was 3.2 per 10000 population (3.7 in women and 2.6 in men). In 2015, nearly 7.3 thousand patients with the diagnosis of $\mathrm{M} 07$ and 6.3 thousand patients with the diagnosis of $L 40.5$ received healthcare benefits. Women accounted for $60.6 \%$ of those patients. Nearly three fourths of PsA patients were aged 40 to 69 years with the median age of 54 years ( 56 years in women and 50 years in men). Between 2008 and 2015 the NFZ expenditure on the treatment of PSA increased from 6.6 million Polish zloty (PLN) (1.9 million EUR) to PLN 50.8 million (12.1 million EUR). In the same period, the number of PsA patients increased from 3.4 thousand to 11.9 thousand. In 2015, the mean cost of treatment per PsA patient was PLN 3.8 thousand.

Conclusions: The PSA prevalence rates estimated by the authors from the NFZ database are clearly lower than those derived from studies in other European countries, which may suggest that the actual number of PSA patients in Poland may be underestimated. Still the number of patients treated for PSA increased nearly 3.5-fold during 2008-2015, when the cost of PsA treatment rose more than 7 times.
\end{abstract}

Key words: psoriatic arthritis, epidemiology, increasing costs of treatment.

\section{Introduction}

Psoriatic arthritis (PSA, diagnostic ICD-10 codes L40.5, M07) is a chronic autoimmune inflammatory disease characterized by peripheral arthritis (usually asymmet- ric), spondylitis, enthesitis and dactylitis in a patient with skin or nail psoriasis [1]. Arthritis may precede the onset of psoriasis. Psoriatic arthritis belongs to a group of rheumatic diseases known as spondyloarthropathies (SpA)

\footnotetext{
Address for correspondence

Anna Kłak, Department of Gerontology and Public Health, National Institute of Geriatrics, Rheumatology and Rehabilitation, Spartańska 1, 02-637 Warsaw, Poland, e-mail: anna.klak@spartanska.pl

Submitted: 2.09.2016; Accepted: 10.11.2016
} 
which have common clinical symptoms and are subdivided into axial (predominantly involving the spine and the sacroiliac joints) and peripheral disease (predominantly involving the peripheral joints). The following types of PSA are distinguished (according to Moll and Wright) [2]:

- oligoarthritis, usually asymmetric (ca. 70\%),

- polyarticular arthritis, resembling rheumatoid arthritis (15-20\%),

- distal interphalangeal joint arthritis predominates, frequently with nail involvement (ca. 5\%),

- arthritis mutilans, severe disabling and disfiguring arthritis (ca. 5\%),

- axial disease, resembling ankylosing spondylitis, but with typical asymmetric inflammation of the sacroiliac joint (ca. 5\%).

The diagnosis of PSA should be based on the new Classification Criteria for Psoriatic Arthritis (CASPAR) published in 2006. Psoriatic arthritis is diagnosed in a patient with inflammatory articular disease: joint, peripheral, spine or entheseal and with at least 3 points from the following criteria presented in Table I [3].

Genetic factors may play a major role in the risk of developing PsA. The HLA antigens B17, Cw6, DR4 and DR7 are much more common in individuals with psoriasis or PsA compared to the general population while the HLA-CW*0602 antigen is frequently associated with early-onset psoriasis and may increase five-fold the likelihood of a patient with psoriasis developing PsA [4-6].
The other factors increasing the risk of PsA are bacterial and viral infections (including streptococcal and human immunodeficiency [HIV] infections), vaccination and BMI [7-9]. Psoriatic arthritis develops more frequently in psoriasis patients with large areas of skin involvement and nail, scalp and intergluteal cleft psoriasis [10]. Environmental and lifestyle factors such as smoking may also play a role in the development of spondyloarthropathy, including PsA, and its course [11].

The metabolic syndrome and hyperuricaemia are comorbidities often associated with PSA and the risk of cardiovascular-complications is from 1- to 5-fold higher than in the general population, which translates to an increased risk of death $[12,13]$. Importantly, this high risk of cardiovascular complications is seen in younger patients in their early thirties.

Estimated rates of PsA prevalence vary but mostly range from 0.1 to $0.35 \%$, i.e. from 10 to 35 cases per 10000 population. In patients with psoriasis the rate is much higher at 6 to 11\% depending on the study. A survey conducted by Anagnostopoulos et al. [14] in Greece shows that PSA is twice as common in women as in men. Table II presents the prevalence of PsA based on the international literature.

According to Poland's Social Insurance Institution (ZUS), in 2014 the number of days of absence from work due to arthropathy associated with psoriasis and enteropathy (M07) was 82514 (76 833 in 2013). In 2014,

Table I. CASPAR - Classification Criteria for Psoriatic Arthritis

Signs of psoriasis (psoriatic lesions on the skin confirmed by rheumatologist of dermatologist); personal or family (presence of psoriasis in $1^{\circ}$ or $2^{\circ}$ degree relative) history -1 point; current psoriasis -2 points.

Typical psoriatic nail dystrophy (oncholysis, pitting and hyperkeratosis) on current examination - 1 point.

Rheumatoid factor (RF) negativity by any method except latex, but preferably ELISA or nephelometry - 1 point.

Dactylitis defined as swelling of an entire digit (sausage-like appearance) current or on history as recorded by rheumatologist -1 point.

Radiographic evidence of bone proliferation seen as ill-defined ossification near joint margins but excluding osteophyte formation on plain X-rays of the hand or foot -1 point.

Source: Modified from [3]

Table II. Psoriatic arthritis: prevalence from European surveys

\begin{tabular}{|c|c|c|c|c|c|c|}
\hline Reference, year & $\begin{array}{l}\text { Year of the } \\
\text { study }\end{array}$ & Country & $\begin{array}{l}\text { Study group } \\
\text { size }\end{array}$ & Prevalence & $95 \% \mathrm{Cl}$ & $\begin{array}{c}\text { Age of the } \\
\text { subjects (years) }\end{array}$ \\
\hline $\begin{array}{l}\text { Anagnostopoulos et al. } \\
2010[14]\end{array}$ & $2007-2008$ & Greece & 1705 & $0.35 \%$ & $0.33-1.33$ & Mean: 41.6 \\
\hline Jordan et al. 2014 [18] & 2010 & $\begin{array}{l}\text { England } \\
\text { Sweden }\end{array}$ & $\begin{array}{c}94565 \\
1243329\end{array}$ & $\begin{array}{l}8 / 10000^{* *} \\
16 / 10000^{* *}\end{array}$ & $\begin{array}{c}6-10 \\
15-17\end{array}$ & No age limits \\
\hline $\begin{array}{l}\text { Lofvendahl et al. } \\
2014 \text { [19] }\end{array}$ & $2005-2010$ & Sweden & 2986 & $0.21 \%$ & $0.20-0.22$ & Mean: 55 \\
\hline Ogdie et al. 2013 [17] & 1994-2010 & United Kingdom & $4.8 \mathrm{~m}$ & $0.19 \%$ & $0.185-0.193 \%$ & $18-90$ \\
\hline
\end{tabular}

** Annual consultation prevalence

Source: Modified from [14-17] 
5236 medical certificates were issued for these conditions (4922 in 2013) [15]. The data refer to people of working age covered by the ZUS insurance. There are no data available for the ICD 10: L40.5 code.

The objective of the study was to analyse the prevalence of PSA in Poland and to assess the costs generated by PsA patients in the system of public health care based on the database of the public payer, the National Health Fund (NFZ).

\section{Material and methods}

The study used a method of so-called desk research, i.e. secondary statistical analysis of data collected for other purposes (e.g. settlement of healthcare benefits). The estimates were based on the databases of the public payer, the National Health Fund (NFZ), which has a single-payer status in Poland. The NFZ databases contain the data of all patients in Poland who received healthcare benefit(s) related to diagnosed PsA, financed from public funds. For the purposes of the analysis, PsA was defined by the diagnostic ICD-10 codes: M07 and L40.5. The NFZ databases were accessed for information about each treated patient with the ICD-10 M07 or L.40.5 codes given as the principal diagnosis or a co-existing disorder in the healthcare benefit settlement report. For the purposes of this paper, a patient with PsA was defined as recipient of at least one healthcare benefit for PsA recorded in the NFZ database. The data used in the analysis were anonymised in compliance with the Polish Act on the Protection of Personal Data.

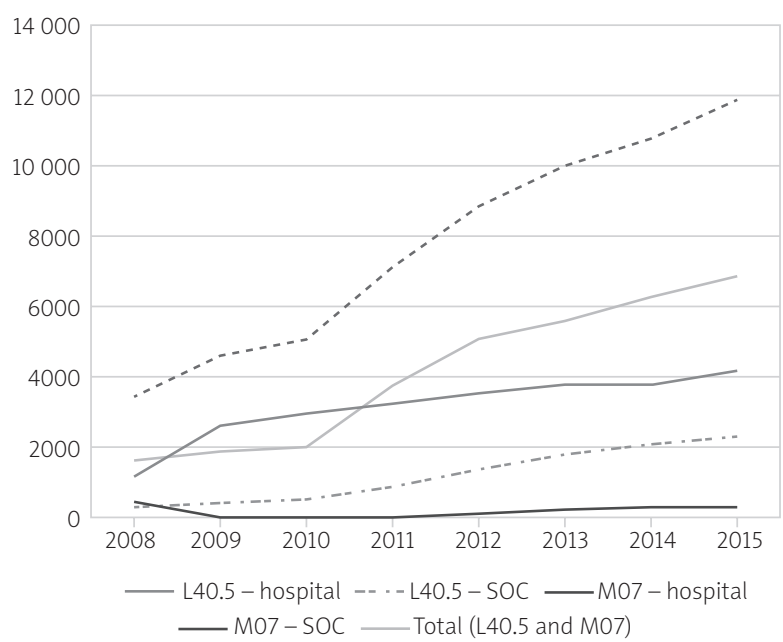

Fig. 1. Number of patients treated for PsA (L40.5 and M07) in Poland with subdivision into outpatient and inpatient care. L40.5 and M07 were the principal diagnoses.
The analysis of the costs was based on the costs reported to the NFZ by health service providers. The total cost of healthcare benefits related to the diagnosis denoted as ICD-10 M07 or L40.5 was calculated for each patient who had received such benefits. The total cost included the cost of the medical procedures and the medicinal products reimbursed within the so-called therapeutic drug programmes (biological treatments), but not patient-incurred cost of prescription drugs.

The prevalence rates were calculated using the NFZ data and the population estimates from the Central Statistical Office of Poland (GUS) [16]. For the purposes of this paper, the PsA prevalence was defined as the ratio of patients who received inpatient basis health care benefits related to the condition coded MO7 or L40.5 to the total size of the population in a given administrative region (voivodeship).

The numbers of physicians practising in particular administrative regions (voivodeships) as of 30 June 2016 were obtained from the Supreme Medical Council (Naczelna Izba Lekarska).

Statistical analyses were performed using the following software: Excel, Statistica 10 and SAS Eg 5.1. The analysis did not include statistical significance tests and no confidence intervals were given since the NFZ data refer to the total population in the territory of Poland.

No ethics committee approval was required as the study was non-invasive and used the data collected by a public institution.

\section{Results \\ Epidemiology}

In Poland, in 2015, nearly 11.9 thousand people received healthcare benefits related to PsA. Of this group, the principal diagnosis was the ICD-10 M07 code in ca. 7.3 thousand cases and the ICD-10 L40.5 code in ca. 6.4 thousand cases $^{1}$. Of the services covered by healthcare benefits related to the diagnosis coded L40.5, 35.6\% were provided on an outpatient basis (specialist outpatient care) and in $64.4 \%$ hospitalization was required. In the case of M07, $94.7 \%$ of patients received treatment on an outpatient basis and $5.3 \%$ were treated on an inpatient basis. In the study period (2008-2015) there was a substantial increase in the number of patients receiving health care benefits because of PsA, from 3.4 thousand in 2008 to 11.9 thousand in 2015 (Fig. 1). Each year the number of PsA patients receiving treatment from the public healthcare system increased by 8 to $40 \%$ in comparison with the previous year. The largest increase was observed in 2011 when the number of people who received healthcare benefits related to PsA grew by 2000 (40\%) in comparison with 2010. From 2008 to 2015, the number of patients

\footnotetext{
${ }^{1}$ The numbers of patients treated for the M07-coded and the L40.5-coded conditions (7.3 thousand and 6.5 thousand respectively) do not add up to 11.9 thousand which was the total number of PsA patients in 2015. This is due to the fact that in a given year a person may receive a number of healthcare benefits, each related to a different diagnosis.
} 
with the diagnosis of L40.5 increased from 1.6 thousand to 6.5 thousand. In the case of the M07 diagnosis, the increase $^{1}$ was from 2.2 to 7.3 thousand.

Women accounted for $60.6 \%$ of patients who in 2015 received healthcare benefits because of PsA. Nearly three fourths of PsA patients were aged 40 to 69 years with the median age of 54 years ( 56 years in women and 50 years in men). The mean age was 52.7 years ( 54.4 years in women and 50.2 years in men).

In 2015, the prevalence of PSA in Poland was 3.2 per 10000 population (3.7 in women and 2.6 in men). The lowest prevalence (1.2) was recorded in men in the Lubusz Voivodeship and the highest prevalence (5.1) in women in the Lublin Voivodeship. The specific data are presented in Table III. The highest prevalence was observed in 55-59-year-olds (8.0 per 10 000). In men, the highest prevalence was in 55-64-year-olds (6.2-6.3) and in women in 50-60-year-olds (8.3-9.6). The specific data are presented in Figure 2.

\section{Expenditure on health care benefits}

In 2015, the National Health Fund (NFZ) spent PLN $50.8 \mathrm{~m}$ (EUR $12.1 \mathrm{~m}$ ) on the healthcare benefits related to Ps A (L40.5, M07). The highest expenditure was on the therapeutic drug programme (71.3\% of the total). Expenditure on hospital treatment and on specialist outpatient care accounted for $26.3 \%$ and $2.4 \%$ of the total expenditure respectively. Between 2008 and 2015 the NFZ expenditure on the treatment of PSA increased nearly 8-fold. Importantly, expenditure on inpatient care was increasing until 2011 (up to PLN $21.1 \mathrm{~m}$, EUR $5.1 \mathrm{~m}$ ). Since the introduction of the therapeutic drug programmes in PsA in 2012, the annual expenditure has remained at the level of 12.4 to $15.1 \mathrm{~m}$ PLN. The annual expenditure on the therapeutic drug programme increased from PLN 14.4 m (EUR 3.4 m) in 2012 to PLN 36.2 m (EUR 8.6 m) in 2015 (from 47\% to 71\% of the total expenditure). In 2012, 453 patients (252 men and 201 women) received treatment within the therapeutic drug programme; in 2013, 662 patients (347 men and 288 women); in 2014, 830 patients (466 men and 364 women); and 2015, 997 patients $-7.3 \%$ of all patients ( 555 men and 442 women).

In the years 2008-2015, the expenditure on the specialist outpatient care (SOC) increased from PLN $0.2 \mathrm{~m}$ (EUR 55 848) to $1.2 \mathrm{~m}$ (EUR 287 833), but remained at the level of 2.2-2.6\% of the total cost of PsA treatment. The specific data are presented in Table IV.

In 2015, the highest expenditure on PsA treatment was at the following regional branches of the NFZ: Silesian (PLN 6.7 m), Lesser Poland (PLN 5.9 m), Greater Poland (PLN $5.6 \mathrm{~m}$ ) and Mazovian (PLN $5.3 \mathrm{~m}$ ).

In 2015, the mean cost of treatment per PsA patient was PLN 3.8 thousand. The highest treatment cost per
Table III. The prevalence of PSA (L40.5 and M07) per 10000 population in the administrative regions (voivodeships) of Poland by gender (2015)

\begin{tabular}{|lccc|}
\hline Voivodeship & Women & Men & Total \\
\hline Dolnośląskie (Lower Silesian) & 4.6 & 3.4 & 4.0 \\
\hline $\begin{array}{l}\text { Kujawsko-pomorskie } \\
\text { (Kuyavian-Pomeranian) }\end{array}$ & 2.7 & 2.0 & 2.4 \\
\hline Lubelskie (Lublin) & 5.1 & 3.8 & 4.5 \\
\hline Lubuskie (Lubus) & 1.6 & 1.2 & 1.4 \\
\hline Łódzkie (Lodz) & 1.9 & 1.7 & 1.8 \\
\hline Małopolskie (Lesser Poland) & 5.0 & 3.1 & 4.1 \\
\hline Mazowieckie (Mazovian) & 4.8 & 3.0 & 4.0 \\
\hline Opolskie (Opole) & 2.7 & 2.3 & 2.5 \\
\hline Podkarpackie (Subcarpathian) & 3.2 & 1.9 & 2.6 \\
\hline Podlaskie & 3.2 & 2.6 & 2.9 \\
\hline Pomorskie (Pomeranian) & 3.2 & 1.9 & 2.5 \\
\hline Śląskie (Silesian) & 4.5 & 3.0 & 3.8 \\
\hline Świętokrzyskie (Holy Cross) & 2.1 & 1.3 & 1.7 \\
\hline Warmińsko-mazurskie & 2.0 & 1.3 & 1.6 \\
(Warmian-Masurian) & & & \\
\hline Wielkopolskie (Greater Poland) & 2.7 & 2.4 & 2.6 \\
\hline $\begin{array}{l}\text { Zachodniopomorskie } \\
\text { (West Pomeranian) }\end{array}$ & 4.5 & 3.2 & 3.9 \\
\hline POLAND & 3.7 & 2.6 & 3.2 \\
\hline
\end{tabular}

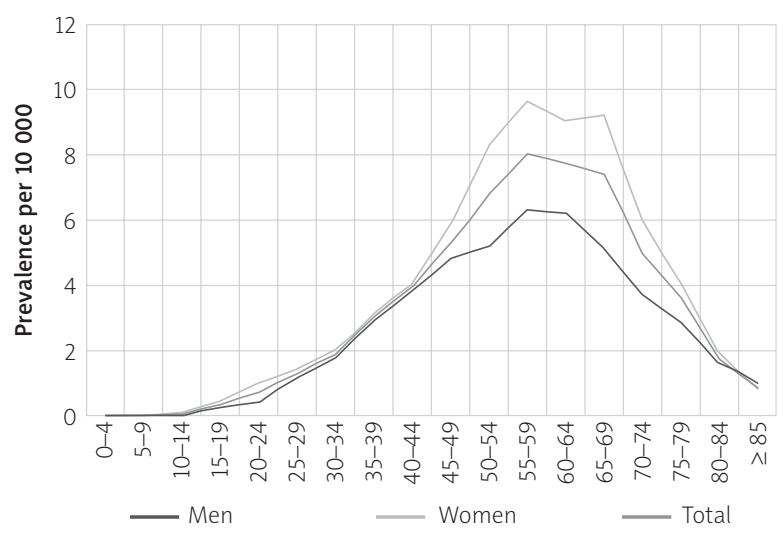

Fig. 2. PsA prevalence (L40.5 and M07) per 10000 population by gender and age (2015).

patient was observed in the following administrative regions (voivodeships) of Poland: Łódź [łódzkie] (PLN 6.9 thousand), Kuyavian-Pomeranian [kujawsko-pomorskie] (PLN 6.9 thousand), Greater Poland [wielkopolskie] (PLN 5.7 thousand) and Holly Cross [świętokrzyskie] (PLN 5.4 thousand) while the following regions reported the lowest treatment cost per patient: Lubus [lubuskie] (PLN 1.9 thousand), Mazovian [mazowieckie] (PLN 2.2 thousand) 
Table IV. NFZ expenditure on PsA treatment (hospitalization, specialist outpatient care and therapeutic drug programmes) in the years 2008-2015

\begin{tabular}{|lcccccccc|}
\hline & 2008 & 2009 & 2010 & 2011 & 2012 & 2013 & 2014 & 2015 \\
\hline $\begin{array}{l}\text { Hospital (without } \\
\text { therapeutic drug } \\
\text { programme) }\end{array}$ & 6374516 & $\begin{array}{c}15437 \\
474\end{array}$ & 17568905 & 21125668 & 15124226 & 14322853 & 12384152 & 13378272 \\
\hline SOC* & 196394 & 251736 & 276102 & 464955 & 798090 & 954125 & 1091093 & 1204263 \\
\hline $\begin{array}{l}\text { Therapeutic drug } \\
\text { programmes }\end{array}$ & & & & & 14362924 & 25940975 & 31524507 & 36244549 \\
\hline $\begin{array}{l}\text { Total (PLN) } \\
\text { 6570910 }\end{array}$ & $\begin{array}{c}15689 \\
210\end{array}$ & 17845007 & 21590623 & 30285241 & 41217953 & 44999752 & 50827084 \\
\hline Total (USD) & 2727424 & 5034725 & 5917368 & 7285761 & 9298508 & 13040355 & 14262544 & 13481628 \\
\hline Total (EUR) & 1868541 & 3625635 & 4467283 & 5240697 & 7236617 & 9819643 & 10752115 & 12148255 \\
\hline Total (PPP GDP**) & 3539388 & 8412310 & 9810641 & 11813907 & 16699461 & 23186478 & 25135496 & 28204708 \\
\hline
\end{tabular}

* specialist outpatient care, ${ }^{* *}$ Purchasing Power Parities for GDP

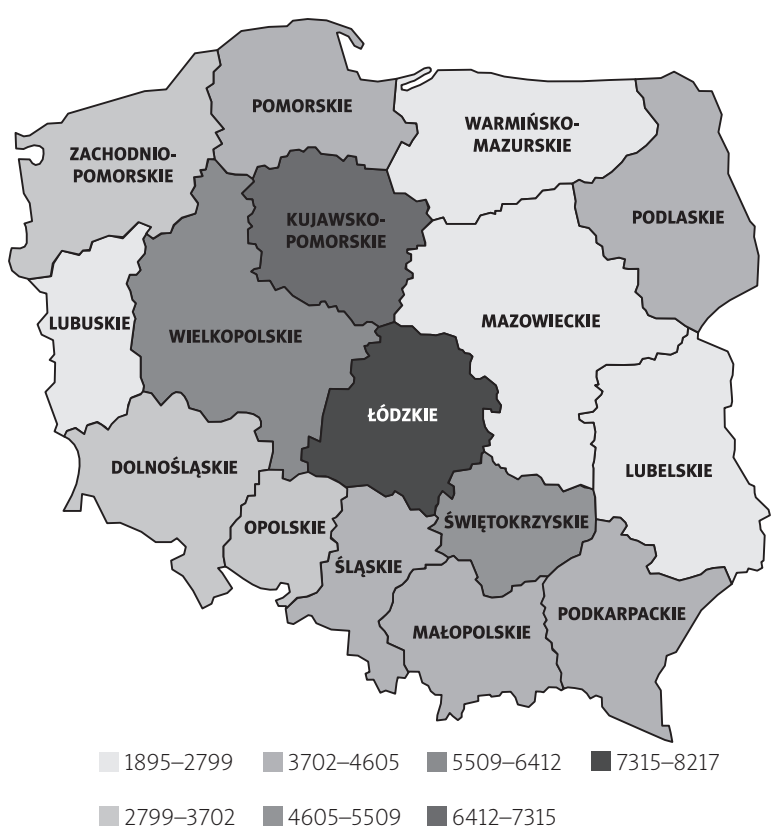

Fig. 3. Mean NFZ expenditure per PsA patient in the administrative regions (voivodeships) of Poland (2015).

and Warmian-Masurian [warmińsko-mazurskie] (PLN 2.4 thousand). The regional differences are presented in Figure 3.

\section{Discussion}

In the years 2008-2015, the number of patients receiving treatment for PsA increased substantially, when the diagnosis was M07 (a 4-fold increase) or L40.5 (a 3-fold increase). We did not find any explanation for such an increase in the number of PsA cases reported in
Poland in the literature on PsA epidemiology [14, 17-19]. The analysis of the prevalence of ankylosing spondylitis in the Polish population in the years 2008-2013 performed employing the same methodology did not reveal a similar phenomenon [20]. The observed increase in PsA prevalence is likely to be associated with improved diagnostic accuracy in PSA achieved with such diagnostic tools as ultrasonography and magnetic resonance imaging. The increased occurrence of PsA may be also due to the increased incidence of obesity in the Polish population, but the role of obesity in the development of PsA requires further studies. Also of importance was the introduction of the therapeutic drug programme in 2012, which improved the access to biological treatments.

Patients with PsA may receive treatment within the therapeutic drug programme when they suffer either from the axial or the peripheral disease. Axial PsA is more common in men and the criteria of inclusion in the programme are similar to those for rheumatoid arthritis patients. For peripheral PSA patients the inclusion criteria are much more difficult to satisfy and the number of patients qualifying for and receiving biological treatment is much lower.

In the present analysis, women accounted for $60.6 \%$ of all patients who were recipients of healthcare benefits related to PSA in 2015, which is similar to the finding of 57.1\% from the study of Lofvendahl et al. [19] while in the study of Ogdie et al. [17] women accounted for just $49.3 \%$ of the study group. In our study, the mean age of patients treated for PsA was slightly higher than that reported in the above studies, 52.7 years vs. 44.8 years in the study of Ogdie et al. [17] and 41.56 years in the study of Anagnostopoulos et al. [14], which may reflect a relative delay in the diagnosis of PSA in Poland.

Our findings of the highest PSA prevalence rates relative to age are similar to the study of Ogdie et al. [17] 
who found the highest prevalence in patients of both genders aged 55-59 years. In our study, the highest prevalence of PsA in men was found for the 55-64 age group, in the study of Ogdie et al. those patients were younger, in the 50-59 age group. In women, the highest prevalence was observed in the 50-69 age group vs. 50-59 age group in the study of Ogdie et al. [17].

The present analysis demonstrated considerable differences in the prevalence of PSA between the administrative regions (voivodeships). In men, the prevalence per 10000 population varied between 1.2 and 3.8 and in women between 1.6 and 5.1. Poland is fairly ethnically homogenous and the differences in age structure between regions cannot account for the variations in prevalence. It may be assumed that the differences may be related to the accessibility of rheumatology and dermatology services and the physicians' competences. We analysed Pearson's linear correlation between the prevalence rates (per 10000 population) and the number (per 10000 population) of rheumatologists and dermatologists practising in a given region. For both rheumatologists and dermatologists, the correlation coefficient was 0.56 . It means that the access to rheumatology services affects (to a limited degree) the prevalence rates for particular regions but does not fully explain the observed differences and further studies are required.

\section{Limitations of the study}

For the purposes of this paper, the analysis was based on the data available from the NFZ, which does not provide a scientific (epidemiological) register.

The study included only codes ICD-10 L40.5 and M07. It is not reflected in the code M09, because due to the nature of data from NFZ it is not possible to clearly distinguish JIA, and JIA in patients with psoriasis. Similarly, it is not possible to fully exclude arthropathy associated with inflammatory bowel diseases.

The data are collected by the NFZ for the purpose of settling healthcare benefits financed from the public funds and health services in the private healthcare sector are not recorded. As a result, with the methodology used (a patient with PSA is defined as each patient receiving in a given year the NFZ-funded healthcare benefits related to PsA as the principal disease entity or a comorbidity) the calculated rates may be underestimated. On the other hand, not all patients recorded as recipients of healthcare benefits related to PsA actually suffered from the disease. This happened especially in the case of individuals who underwent diagnostic tests for suspected PsA which did not confirm that diagnosis with the resulting overestimation of the prevalence rates.

Because of that, an additional analysis was performed on the data from the entire 2008-2015 period.
Outpatient services (SOC) financed from the public funds were used at least once by 20.4 thousand patients. Of that group, 6.7 thousand patients attended one consultation only and 3.1 thousand patients attended two consultations. The remaining 10.7 thousand patients attended three or more consultations. These figures are close to the estimated numbers of patients with PsA in the years 2013, 2014 and 2015 (10 thousand, 10.7 thousand and 11.9 thousand respectively).

\section{Strengths of the study}

The analysis is based on the official data from the territory of Poland. The data are collected for the entire insured population. The analysis covered the years 20082015, i.e. eight healthcare benefit settlement periods.

\section{Conclusions}

The prevalence rates of psoriatic arthritis calculated for Poland on the basis of the NFZ data are clearly lower than those reported from other European countries which may indicate that the prevalence of PsA in Poland is underestimated. This is supported by a nearly 3.5-fold increase in the number of patients treated for PsA in the period analysed and it may be assumed that the trend will continue.

The expenditure by the NFZ related to PSA systematically increased in the years 2008-2015 which was related to the growing spending on the therapeutic drug programmes.

The authors declare no conflict of interest.

\section{References}

1. Stanisławska-Biernat E, Świerkot J, Tłustochowicz W. Spondyloartropatie. Reumatologia 2012; 50: 93-102.

2. Olivieri I, D’Angelo S, Gilio M, et al. Relationship of Psoriatic Arthritis to Other Spondyloarthritides. J Rheumatol Suppl 2015; 93: 33-35.

3. Taylor W, Gladman D, Helliwell P, et al. Classification criteria for psoriatic arthritis: development of new criteria from a large international study. Arthritis Rheum 2006; 54: 2665-2673.

4. Queiro R, Moreno P, Sarasqueta C, et al. Synovitis-acne-pustulosis-hyperostosis-osteitis syndrome and psoriatic arthritis exhibit a different immunogenetic profile. Clin Exp Rheumatol 2008; 26: 125-128.

5. Queiro-Silva R, Torre-Alonso JC, Tinturé-Eguren T, et al. The effect of HLA-DR antigens on the susceptibility to, and clinical expression of psoriatic arthritis. Scand J Rheumatol 2004; 33: 318-322.

6. Ho Pauline YPC, Barton A, Worthington J, et al. Investigating the role of the HLA-CW*06 and HLA-DRB1 genes in susceptibility to psoriatic arthritis: comparison with psoriasis and undifferentiated inflammatory arthritis. Ann Rheum Dis 2008; 67: 677-682. 
7. Adizie T, Moots RJ, Hodkinson B, et al. Inflammatory arthritis in HIV positive patients: A practical guide. BMC Infect Dis 2016; 16: 100.

8. Manasson J, Scher JU. Spondyloarthritis and the microbiome: new insights from an ancient hypothesis. Curr Rheumatol Rep 2015; 17: 10.

9. Love TJ, Zhu Y, Zhang Y, et al. Obesity and the risk of psoriatic arthritis: a population-based study. Ann Rheum Dis 2012; 71: 1273-1277.

10. Wilson FC, Icen M, Crowson CS, et al. Incidence and clinical predictors of psoriatic arthritis in patients with psoriasis: a population-based study. Arthritis Rheum 2009; 61: 233-239.

11. Ogdie A, Gelfand JM. Clinical Risk Factors for the Development of Psoriatic Arthritis Among Patients with Psoriasis: A Review of Available Evidence. Curr Rheumatol Rep 2015; 17: 64.

12. Huang YP, Wang Yh, Pan SL. Increased risk of ischemic heart disease in young patients with newly diagnosed ankylosing spondylitis - a population-based longitudinal follow-up study. PloS One 2013; 8: e64155.

13. Daïen $\mathrm{Cl}$, Sellam J. Obesity and inflammatory arthritis: impact on occurrence, disease characteristics and therapeutic response. RMD Open 2015; 1: e000012.

14. Anagnostopoulos I, Zinzaras E, Alexiou I, et al. The prevalence of rheumatic diseases in central Greece: a population survey. BMC Musculoskeletal Dis 2010; 11: 98.
15. Social Insurance Institution (2015) Statistical Portal http:// www.psz.zus.pl/Default.aspx. Accessed 30 June 2016 Polish.

16. Population. Status and structure of the population and its migration by administrative regions http://stat.gov.pl/ obszary-tematyczne/ludnosc/ludnosc/ludnosc-stan-i-struktura-ludnosci-oraz-ruch-naturalny-w-przekroju-terytorialnym-stan-w-dniu-30-vi-2015-r-,6,18.html Accessed 26 June 2016 Polish.

17. Ogdie A, Langan S, Love T, et al. Prevalence and treatment patterns of psoriatic arthritis in the UK. Rheumatology 2013; 52: 568-575.

18. Jordan KP, Jöud A, Bergknut C, et al. International comparisons of the consultation prevalence of musculoskeletal conditions using population-based healthcare data from England and Sweden. Ann Rheum Dis 2014; 73: 212-218.

19. Lofvendahl S, Theander E, Svensson A, et al. Validity of Diagnostic Codes and Prevalence of Physician-Diagnosed Psoriasis and Psoriatic Arthritis in Southern Sweden - A Population-Based Register Study. PLoS ONE 2014; 9: e98024.

20. Śliwczyński A, Raciborski F, Kłak A, et al. Prevalence of ankylosing spondylitis in Poland and costs generated by AS patients in the public healthcare system. Rheumatol Int 2015; 35: 1361-1367. 